\title{
lonospheric Propagation Effects on GNSS Signals and New Correction Approaches
}

\author{
M. Mainul Hoque and Norbert Jakowski \\ German Aerospace Center (DLR), Institute of Communications and Navigation \\ Neustrelitz, \\ Germany
}

\section{Introduction}

The ionosphere is the ionized part of the earth's atmosphere lying between about $50 \mathrm{~km}$ and several earth radii (Davies, 1990) whereas the upper part above about $1000 \mathrm{~km}$ height up to the plasmapause is usually called the plasmasphere. Solar extreme ultraviolet (EUV) radiation at wave lengths $<130 \mathrm{~nm}$ significantly ionizes the earth's neutral gas. In addition to photoionisation by electromagnetic radiation also energetic particles from the solar wind and cosmic rays contribute to the ionization. The ionized plasma can affect radio wave propagation in various ways modifying characteristic wave parameters such as amplitude, phase or polarization (Budden, 1985; Davies, 1990). The interaction of the radio wave with the ionospheric plasma is one of the main reasons for the limited accuracy and vulnerability in satellite based positioning or time estimation.

A trans-ionospheric radio wave propagating through the plasma experiences a propagation delay / phase advance of the signal causing a travel distance or time larger / smaller than the real one. The reason of the propagation delay can be realized considering the nature of the refractive index which depends on the density of the ionospheric plasma. The refractive index $(n \neq 1)$ of the ionosphere is not equal to that of free space $(n=1)$. This causes the propagation speed of radio signals to differ from that in free space. Additionally, spatial gradients in the refractive index cause a curvature of the propagation path. Both effects lead in sum to a delay / phase advance of satellite navigation signals in comparison to a free space propagation.

The variability of the ionospheric impact is much larger compared to that of the troposphere. The ionospheric range error varies from a few meters to many tens of meters at the zenith, whereas the tropospheric range error varies between two to three meters at the zenith (Klobuchar, 1996). The daily variation of the ionospheric range error can be up to one order of magnitude (Klobuchar, 1996).

After removal of the Selective Availability (SA, i.e., dithering of the satellite clock to deny full system accuracy) in 2000, ionosphere becomes the single largest error source for Global Navigation Satellite Systems (GNSS) users, especially for high-accuracy (centimeter millimeter) applications like the Precise Point Positioning (PPP) and Real Time Kinematic (RTK) positioning. Fortunately, the ionosphere is a dispersive medium with respect to the 
radio wave; therefore, the magnitude of the ionospheric delay depends on the signal frequency. The advantage is that an elimination of the major part of the ionospheric refraction through a linear combination of dual-frequency observables is possible. However, inhomogeneous plasma distribution and anisotropy cause higher order nonlinear effects which are not removed in this linear approach. Mainly the second and third order ionospheric terms (in the expansion of the refractive index) and errors due to bending of the signal remain uncorrected. They can be several tens of centimeters of range error at low elevation angles and during high solar activity conditions.

Brunner \& Gu (1991) were pioneers to compute higher order ionospheric effects and developing correction for them. Since then higher order ionospheric effects have been studied by different authors during last decades, e.g., Bassiri \& Hajj (1993), Jakowski et al. (1994), Strangeways \& Ioannides (2002), Kedar et al. (2003), Fritsche et al. (2005), Hawarey et al. (2005), Hoque \& Jakowski (2006, 2007, 2008, 2010b), Hernández-Pajares et al. (2007), Kim \& Tinin (2007, 2011), Datta-Barua et al. (2008), Morton et al. (2009), Moore \& Morton (2011). The above literature review shows that higher order ionospheric terms are less than $1 \%$ of the first order term at GNSS frequencies. Hernández-Pajares et al. (2007) found submillimeter level shifting in receiver positions along southward direction for low latitude receivers and northward direction for high latitude receivers due to the second order term correction. Fritsche et al. (2005) found centimeter level correction in GPS satellite positions considering higher order ionospheric terms. Elizabeth et al. (2010) investigated the impacts of the bending terms described by Hoque \& Jakowski (2008) on a Global Positioning System (GPS) network of ground receivers. They found the bending correction for the dualfrequency linear GPS L1-L2 combination to exceed the $3 \mathrm{~mm}$ level in the equatorial region. Kim \& Tinin (2011) found that the systematic residual ionospheric errors can be significantly reduced (under certain ionospheric conditions) through triple frequency combinations. All these studies were conducted to compute higher order ionospheric effects on GNSS signals for ground-based reception. Recently Hoque \& Jakowski $(2010 b, 2011)$ investigated the ionospheric impact on GPS occultation signals received onboard Low Earth Orbiting (LEO) CHAMP (CHAllenging Minisatellite Payload) satellite.

In this chapter, the first and higher order ionospheric propagation effects on GNSS signals are described and their estimates are given at different level of ionospheric ionization. Multi-frequency ionosphere-free and geometry-free solutions are studied and residual terms in the ionosphere-free solutions are computed. Different correction approaches are discussed for the second and third order terms, and ray path bending correction. Additionally, we have proposed new approaches for correcting straight line of sight (LoS) propagation assumption error, i.e., ray path bending error for ground based GNSS positioning. We have modelled the excess path length of the signal in addition to the LoS path length and the total electron content (TEC) difference between a curved and LoS paths as functions of signal frequency, ionospheric parameters such as TEC and TEC derivative with respect to the elevation angle. We have found that using the TEC derivative in addition to the TEC information we can improve the existing correction results.

\section{2. lonospheric propagation effects}

Quantitatively, the propagation of a radio wave through the ionospheric plasma is described by the refractive index of the ionosphere (Appleton-Hartree formula). At high 
frequencies (> $100 \mathrm{MHz}$ ), the refractive index mainly depends on the electron density, the strength and direction of the geomagnetic field in relation to the ray path. Thus, the spatial distribution of the electron density along the ray path and corresponding geomagnetic field relationships determine the ionospheric impact on the electromagnetic wave.

\section{1 lonospheric refractive index}

For high frequency (HF) radio waves with frequencies $f>100 \mathrm{MHz}$ the phase refractive index $n$ can be derived from the Appleton - Hartree formula as (Appleton, 1932; Bassiri \& Hajj, 1993)

$$
n=1-\frac{f_{p}^{2}}{2 f^{2}} \pm \frac{f_{p}^{2} f_{g} \cos \Theta}{2 f^{3}}-\frac{f_{p}^{2}}{4 f^{4}}\left[\frac{f_{p}^{2}}{2}+f_{g}^{2}\left(1+\cos ^{2} \Theta\right)\right]
$$

in which

$f_{p}^{2}=n_{e} e^{2} /\left(4 \pi^{2} \varepsilon_{0} m\right)$

$f_{g}=e B /(2 \pi m)$

where $f_{p}$ is the plasma frequency, $f_{g}$ is the gyro frequency, $\varepsilon_{0}$ is the free space permittivity, $B$ is the geomagnetic induction, $\Theta$ is the angle between the wave propagation direction and the geomagnetic field vector $\boldsymbol{B}$, and $e, n_{e}, m$ are the electron charge, density and mass, respectively. The wave with the upper $(+)$ sign in Eq. (1) is called the ordinary wave and is left-hand circularly polarized, whereas the wave with the lower (-) sign is called the extraordinary wave and is right-hand circularly polarized (Hartmann \& Leitinger, 1984). The GPS signals are transmitted in right-hand circular polarization (Parkinson \& Gilbert, 1983).

Equation (1) indicates that the phase refractive index is less than the unity resulting in a phase velocity that is greater than the speed of light in vacuum (i.e., phase advance). Therefore, the integration of $n$ along a signal path gives a measure of the range / travel time between a receiver and a satellite that is smaller than the geometric distance / travel time in the vacuum.

To compute group delay measurements, the group refractive index $n_{g r}$ should be considered. The expression for $n_{g r}$ can be determined by the relationship $n_{g r}=n+f(d n / d f)$.

$$
n_{g r}=1+\frac{f_{p}^{2}}{2 f^{2}} \mp \frac{f_{p}^{2} f_{g} \cos \Theta}{f^{3}}+\frac{3 f_{p}^{2}}{4 f^{4}}\left[\frac{f_{p}^{2}}{2}+f_{g}^{2}\left(1+\cos ^{2} \Theta\right)\right]
$$

Equation (2) indicates that the group refractive index is greater than the unity resulting in a group velocity that is less than the speed of light. Therefore, the integration of $n_{g r}$ along a signal path gives a measure of the range / travel time that is greater than the geometric distance / travel time in the vacuum. Therefore, when GNSS signals propagate through the ionosphere, the carrier-phase experiences an advance and the code experiences a group delay. The carrier-phase pseudoranges are measured too short and the code pseudoranges are measured too long compared to the geometric range between a satellite and a receiver. 
Considering ionospheric refraction the geometric distance (Euclidean line) or true range $\rho$ between a transmitting satellite $S$ and a receiver $R$ can be written in units of length as

$$
\rho=L+\int_{S}^{R}(1-n) d s-d_{I}^{l e n}
$$

where the optical distance $L=\int_{S}^{R} n d s$ is the line integral of the refractive index between the satellite and the receiver along the ray path, $\int_{S}^{R}(1-n) d s$ is the ionospheric group delay and $d_{I}^{\text {len }}$ is the excess path length of the signal in addition to the geometric path length caused by the ray path bending and defined by

$$
d_{I}^{l e n}=\int_{S}^{R} d s-\rho
$$

where $\int_{S}^{R} d s$ is the curved path length in the vacuum. The travel time of the signal can be computed dividing the expression of $\rho$ (Eq. 3) simply by the speed of light.

\subsection{Group delay and phase advance}

Assuming a right hand circularly polarized signal, the ionospheric group delay $d_{I g r}$ and carrier phase advance $d_{I}$ can be written in units of length as (using Eqs. (1) and (2))

$$
\begin{gathered}
d_{I g r}=d_{I g r}^{(1)}+d_{I g r}^{(2)}+d_{I g r}^{(3)}=\int_{S}^{R}\left(n_{g r}-1\right) d s=\frac{p}{f^{2}}+\frac{q}{f^{3}}+\frac{u}{f^{4}} \\
d_{I}=d_{I}^{(1)}+d_{I}^{(2)}+d_{I}^{(3)}=\int_{S}^{R}(1-n) d s=\frac{p}{f^{2}}+\frac{q}{2 f^{3}}+\frac{u}{3 f^{4}} \\
p=K \int n_{e} d s=K \cdot T E C=K\left(T E C_{\text {LoS }}+\Delta T E C_{b e n d}\right) \\
q=2.2566 \times 10^{12} \int n_{e} B \cos \Theta \cdot d s \\
u=2437 \int n_{e}^{2} d s+4.74 \times 10^{22} \int n_{e} B^{2}\left(1+\cos ^{2} \Theta\right) d s
\end{gathered}
$$

where $K=e^{2} /\left(8 \pi^{2} \varepsilon_{0} m\right)=40.3 \mathrm{~m}^{3} \mathrm{~s}^{-2}$, the integration of $n_{e}$ along signal paths $\int n_{e} d s$ is called the total electron content TEC and measured in TEC units ( 1 TECU $=10^{16}$ electrons $\left./ \mathrm{m}^{2}\right)$. The terms $d_{I g r}^{(1)} / d_{I}^{(1)}, d_{I g r}^{(2)} / d_{I}^{(2)}$ and $d_{I g r}^{(3)} / d_{I}^{(3)}$ in Eq. (5) / (6) are the first, second and third order ionospheric group delays / phase advances, respectively. Due to the dispersive nature of the ionosphere, satellite signals transmitted on different frequencies travel along different 
ray paths through the ionosphere on their way to a receiver and thus the TEC along a $f_{1}$ path will be different from that along a $f_{2}$ path and also from that along the LoS path. Considering this, TEC in Eq. (7) is separated into TEC LoS and $\triangle T E C_{\text {bend }}$ where $T E C_{L o S}$ is the TEC along the LoS and $\triangle T E C_{b e n d}$ is the difference between TECs along a curved path and the LoS path. The term $\triangle T E C_{\text {bend }}$ represents TEC contribution due to ray path bending only, i.e., the second and third order terms are not considered in TEC estimation by Eq. (7).

\section{3 lonospheric effects on GNSS observables}

The observables are travel time or ranges which are deduced from measured time or phase differences based on a comparison between received signals and receiver generated signals. Thus, the ranges are biased by satellite and receiver clock errors, instrumental biases and atmospheric effects, and therefore, called pseudoranges. The code pseudorange $(\Psi)$ and carrier-phase pseudorange $(\Phi)$ at a selected frequency can be described by observation equations in units of length as

$$
\begin{gathered}
\Psi=\rho+c(d t-d T)+d_{I g r}+d_{A}+\left(d_{M P}\right)_{\Psi}+d q+d Q+\varepsilon_{\Psi} \\
\Phi=\rho+c(d t-d T)-d_{I}+d_{A}+\left(d_{M P}\right)_{\Phi}+d q+d Q+N \lambda+\varepsilon_{\Phi}
\end{gathered}
$$

where $\rho$ is the geometric distance between a satellite and a receiver, $c$ is the velocity of light, $d t$ and $d T$ are the satellite and receiver clock errors, respectively, $d_{I}$ and $d_{I g r}$ are the ionospheric effects on carrier-phase and code pseudoranges, respectively, $d_{A}$ is the atmospheric (tropospheric delay) effect, $\left(d_{M P}\right) \Psi$ and $\left(d_{M P}\right)_{\Phi}$ are multipath effects on code and carrier-phase pseudoranges, respectively, $d q$ and $d Q$ are the instrumental biases of the satellite and the receiver, respectively, $\lambda$ is the carrier wavelength, $N$ is the integer carrierphase ambiguity, and $\varepsilon_{\Psi}$ and $\varepsilon_{\Phi}$ are the rest errors. The carrier-phase pseudorange is expressed in units of length (meters) instead of cycles. However, it can be expressed in cycles dividing simply by the signal's wave length ( $\lambda$ meter/cycle).

For simplicity we confine our interest to only ionospheric effects. Thus, the code and carrierphase pseudoranges can be simplified as

$$
\begin{aligned}
& \Psi=\rho+d_{I g r}+d_{I}^{l e n}=\rho+\frac{p}{f^{2}}+\frac{q}{f^{3}}+\frac{u}{f^{4}}+d_{I}^{l e n} \\
& \Phi=\rho-d_{I}+d_{I}^{l e n}=\rho-\frac{p}{f^{2}}-\frac{q}{2 f^{3}}-\frac{u}{3 f^{4}}+d_{I}^{l e n}
\end{aligned}
$$

where $f$ is the signal frequency. In case of GPS L1, L2 and L5 signals $f=1575.42,1227.6$ and 1176.45 MHz, respectively. To take into account the ray path bending on observables, the term $d_{I}^{\text {len }}$ is introduced in Eqs. (12) and (13).

\subsection{Multi-frequency combinations}

\subsubsection{First order ionosphere-free combination}

As already mentioned, ionosphere is a dispersive medium, i.e., the ionospheric propagation delay is frequency dependent. Therefore, one very popular way to get rid of ionospheric 
effects is to compute the so called first order ionosphere-free combination of carrier-phase or code pseudoranges measured on two frequencies. However, the second and third order ionospheric terms and errors due to bending of the signal remain uncorrected in this approach. Such a dual-frequency combination can be written in units of length as (combining code / carrier-phase pseudoranges Eq. (12) / Eq. (13) measured on $f_{1}$ and $f_{2}$ frequencies and substituting $p$ by Eq. (7), for details see Hoque \& Jakowski, 2008)

$$
\begin{gathered}
\frac{f_{1}^{2}}{f_{1}^{2}-f_{2}^{2}} \Psi_{1}-\frac{f_{2}^{2}}{f_{1}^{2}-f_{2}^{2}} \Psi_{2}=\rho \underbrace{-\Delta s_{T E C}-2 \Delta s_{2}-3 \Delta s_{3}-\Delta s_{l e n}}_{R R E_{g r}} \\
\frac{f_{1}^{2}}{f_{1}^{2}-f_{2}^{2}} \Phi_{1}-\frac{f_{2}^{2}}{f_{1}^{2}-f_{2}^{2}} \Phi_{2}=\rho \underbrace{\rho+\Delta s_{T E C}+\Delta s_{2}+\Delta s_{3}-\Delta s_{l e n}}_{R R E} \\
\Delta s_{T E C}=\frac{K\left(T E C_{2}-T E C_{1}\right)}{\left(f_{1}^{2}-f_{2}^{2}\right)}=\frac{K\left(\Delta T E C_{\text {bend } 2}-\Delta T E C_{\text {bend } 1}\right)}{\left(f_{1}^{2}-f_{2}^{2}\right)} \\
T E C_{1,2}=\int n_{e} d s=\left(T E C_{\text {LoS }}+\Delta T E C_{b e n d 1,2}\right) \\
\Delta s_{2}=\frac{q}{2 f_{1} f_{2}\left(f_{1}+f_{2}\right)} \\
\Delta s_{3}=\frac{u}{3 f_{1}^{2} f_{2}^{2}} \\
\Delta s_{l e n}=\frac{d_{2}^{l e n} f_{2}^{2}-d_{1}^{l e n} f_{1}^{2}}{\left(f_{1}^{2}-f_{2}^{2}\right)}
\end{gathered}
$$

where $\Psi_{1}, \Psi_{2}$ and $\Phi_{1}, \Phi_{1}$ are the measured code and carrier-phase pseudoranges on $f_{1}$ and $f_{2}$ frequencies, respectively, $\Delta s_{2}$ and $\Delta s_{3}$ are the dual-frequency second and third order residual terms, respectively. The TEC along a $f_{1}$ path will be different from that along a $f_{2}$ path due to ray path bending. Due to the same reason the excess path length will not be the same for both signals. Therefore, they will not be cancelled out in the ionosphere-free solution. Thus, the terms $\Delta s_{T E C}$ and $\Delta s_{\text {len }}$ in Eq. (14) and (15) refer to the dual-frequency residual errors due to TEC difference and excess path length, respectively. Their expressions are given by Eqs. (16) and (20). The quantities $\triangle T E C_{\text {bend1 } 1}$ and $\triangle T E C_{\text {bend } 2}$ are the differences between TECs along curved and LoS paths and the quantities $d_{1}^{\text {len }}$ and $d_{2}^{\text {len }}$ are the differences between curved and LoS path lengths for $f_{1}$ and $f_{2}$ signals, respectively. The RRE and RRE gr are the total residual range errors in the carrier-phase and code combinations, respectively.

The disadvantages of such combinations (Eqs. 14, 15) are that i) the observation noise is increased by a factor depending on frequencies involved in the combination, ii) the ambiguity term of the carrier-phase combination is no more an integer value and iii) only the first order term is eliminated, i.e., higher order terms remain uncorrected. Moreover, this method cannot be applied to single-frequency receivers. 
Assuming the same measurement noise on each signal, it can be shown that the carrierphase or code noise will be amplified by a factor of 2.98 for the GPS L1-L2 combination, whereas for the L1-L5 and L2-L3 combinations amplification factors are 2.59 and 16.64, respectively (see Hoque \& Jakowski, 2010a). The amplification factor is inversely proportional to the separation of combination frequencies. Since the frequency separation is relatively large for the L1-L5 combination, the amplification factor is the smallest.

Since the first order ionospheric effect on carrier-phase and code pseudoranges (see Eq. 12 and 13) is the same in magnitude but opposite in sign, computing the sum of carrier-phase and code pseudoranges would theoretically eliminate the first order ionospheric term in single frequency measurements. However, the resulting observable would inherit the high code noise and the carrier-phase ambiguity and is therefore, practically not suitable.

\subsubsection{Second order ionosphere-free combination}

Receiving signals on three coherent frequencies will allow triple-frequency combinations to eliminate the first and the second order ionospheric terms. The third order ionospheric term and errors due to ray path bending are not fully removed in this approach. Such a triplefrequency combination can be written as (combining code / carrier-phase pseudoranges Eq. (12) / Eq. (13) measured on $f_{1}, f_{2}$ and $f_{3}$ frequencies and substituting $\rho$ by Eq. (7), for details see Hoque \& jakowski, 2010a).

$$
\begin{aligned}
& \frac{1}{C}\left[A\left(\Psi_{1} f_{1}^{2}-\Psi_{2} f_{2}^{2}\right)-B\left(\Psi_{1} f_{1}^{2}-\Psi_{3} f_{3}^{2}\right)\right]=\rho \underbrace{+\left(\Delta s_{T E C}\right)_{t r}+3\left(\Delta s_{3}\right)_{t r}+\left(\Delta s_{l e n}\right)_{t r}}_{\left(R R E_{g r}\right)_{t r}} \\
& \frac{1}{C}\left[A\left(\Phi_{1} f_{1}^{2}-\Phi_{2} f_{2}^{2}\right)-B\left(\Phi_{1} f_{1}^{2}-\Phi_{3} f_{3}^{2}\right)\right]=\rho \underbrace{-\left(\Delta s_{T E C}\right)_{t r}-\left(\Delta s_{3}\right)_{t r}+\left(\Delta s_{l e n}\right)_{t r}}_{(R R E)_{t r}}
\end{aligned}
$$

In which

$$
\begin{gathered}
\left(\Delta s_{T E C}\right)_{t r}=\frac{K}{C}\left[B\left(\Delta T E C_{\text {bend } 3}-\Delta T_{E C} C_{\text {bend } 1}\right)-A\left(\Delta T E C_{\text {bend } 2}-\Delta \mathrm{TEC}_{\text {bend } 1}\right)\right] \\
\left(\Delta s_{3}\right)_{t r}=\frac{u}{3 C} \frac{\left(f_{2}-f_{3}\right)}{f_{2} f_{3}} \\
\left(\Delta s_{\text {len }}\right)_{t r}=\frac{1}{C}\left[B\left(f_{3}^{2} d_{3}^{l e n}-f_{1}^{2} d_{1}^{l e n}\right)-A\left(f_{2}^{2} d_{2}^{l e n}-f_{1}^{2} d_{1}^{l e n}\right)\right] \\
\left.\begin{array}{c}
A=\frac{f_{1} f_{2}}{f_{1}-f_{2}} \\
B=\frac{f_{1} f_{3}}{f_{1}-f_{3}} \\
C=f_{1}\left(f_{2}-f_{3}\right)\left(f_{1}+f_{2}+f_{3}\right)
\end{array}\right\}
\end{gathered}
$$


where $K=40.3 \mathrm{~m}^{3} \mathrm{~s}^{-2}, \Psi$ and $\Phi$ are the code and carrier-phase pseudoranges, and their subscripts correspond to measured signals on $f_{1}, f_{2}$ and $f_{3}$ frequencies, $\left(\Delta s_{3}\right)$ tr is the third order residual term and $\left(\Delta s_{T E C}\right)_{t r}$ and $\left(\Delta s_{\text {len }}\right)_{t r}$ are the residual terms due to TEC difference and excess path length, respectively. The quantities $\triangle T E C_{\text {bend }}$ and $d_{l}{ }^{\text {len }}$ are the TEC and path length differences between curved and LoS paths and and their subscripts correspond to received signals on frequencies $f_{1}, f_{2}$ and $f_{3}$. The $(R R E)_{t r}$ and $(R R E g r)_{\text {tr }}$ are the total residual range errors in the triple-frequency carrier-phase and code pseudorange combinations, respectively.

However, as already mentioned, such a multiple frequency combination amplifies all uncorrelated errors or noises (multipath and noise). Assuming the same measurement noise on each signal, it can be shown that the noise will be amplified by a factor of 33.7 in the GPS L1-L2-L5 combination (see Hoque \& Jakowski, 2010a).

The Galileo system will transmit signals on four frequencies E2-L1-E1, E5a, E5b and E6 (1575.42, 1176.45, 1207.14 and $1278.75 \mathrm{MHz}$, respectively). Simultaneous reception of four signals will allow quadruple-frequency combinations to eliminate the first, second and third order ionospheric terms. Such a combination would theoretically eliminate higher order ionospheric terms successfully from the range equation. However, the noise will be amplified by a factor of about 626.13 in the E2L1E1-E5a-E5b-E6 combination (assuming the same measurement noise on each signal) which is about two orders larger than a dualfrequency factor. Therefore, a quadruple-frequency combination is barely pragmatic. However, if the frequency separation is large (e.g., combinations between $4-8 \mathrm{GHz} \mathrm{C}$ band and 1-2 GHz L band frequencies), the amplification factor will be small. In such cases, measurements on four frequencies may be useful.

\subsubsection{Geometry-free combination}

When microwave signals are transmitted on two frequencies, all the nondispersive effects, e.g., tropospheric delay, satellite and receiver clock offsets, antenna phase centre offsets and variations etc., manipulate the signals on both frequencies in the same way - apart from the ionosphere. Therefore, by differencing code / carrier-phase pseudoranges measured on two frequencies, all non-dispersive terms including $\rho$ will be cancelled out giving the estimate of TEC along ray paths as (combining code / carrier-phase pseudoranges Eq. (12) / Eq. (13) measured on $f_{1}$ and $f_{2}$ frequencies and substituting $\rho$ by Eq. (7) and neglecting the second and higher order terms)

$$
\begin{gathered}
\text { TEC }=\frac{f_{1}^{2} f_{2}^{2}}{K\left(f_{1}^{2}-f_{2}^{2}\right)}\left[\left(\Psi_{2}-\Psi_{1}\right)+\text { noise }_{\Psi_{2}-\Psi_{1}}\right] \\
\text { TEC }=\frac{f_{1}^{2} f_{2}^{2}}{K\left(f_{1}^{2}-f_{2}^{2}\right)}\left[\left(\Phi_{1}-\Phi_{2}\right)+B_{\text {ambiguity }}+\text { noise }_{\Phi_{1}-\Phi_{2}}\right]
\end{gathered}
$$

in which $B_{\text {ambiguity }}=\lambda_{2} N_{2}-\lambda_{1} N_{1}$ is the carrier-phase ambiguity constant where $\lambda_{1}, \lambda_{2}$ are wave lengths and $N_{1}, N_{2}$ are integer ambiguities measured on $f_{1}$ and $f_{2}$ frequencies, noise $\Psi_{2}-\Psi_{1}$ and noise $_{\Phi_{1}-\Phi_{2}}$ are noises (e.g., thermal noise etc.) in code and carrier-phase combinations, respectively. For simplicity different terms such as inter-frequency satellite and receiver biases and multipath effects are not considered. 

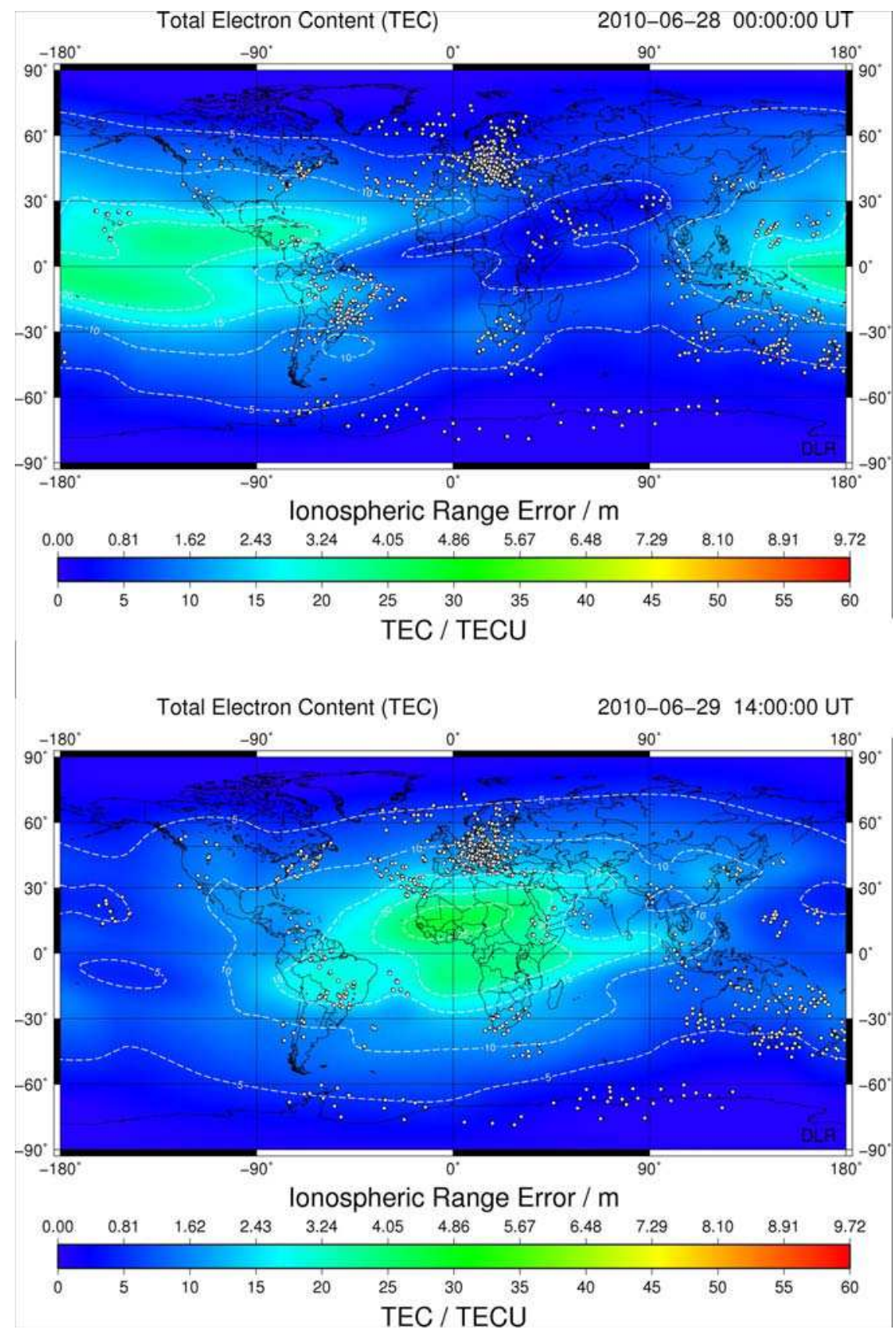

Fig. 1. Examples of global TEC maps and corresponding ionospheric range errors at GPS L1 during night time (0 UT) and day time (14 UT) (http:/ / swaciweb.dlr.de). The dots represent IPP locations 
In case of cycle slips (a jump in carrier-phase ambiguity constant due to loss of signal tracking results in discontinuous arcs of phase data) in the phase data, the wide-lane combination method of Blewitt (1987) can be applied for the correction. While the TEC estimated by the carrier-phase difference Eq. (28) is precise and smooth but biased by an unknown phase ambiguity constant, the TEC estimated by the code pseudorange difference Eq. (27) is noisy and less precise but not ambiguous. In order to obtain an absolute and precise estimate of TEC, the accurate phase measurements needs to be levelled to the calibrated absolute code measurements by a least square method.

To derive an elevation independent vertical TEC from a slant TEC measurement, the ionosphere is assumed to be composed of a single thin layer at a representative height of about 350, 400 or $450 \mathrm{~km}$ from the earth's surface. The intersection point between a slant ray path and the thin layer is called an ionospheric piercing point (IPP). A mapping function is used to convert the slant STEC to vertical VTEC at the IPP or vice versa (details of the derivation is given in Hoque \& Jakowski, 2008).

$$
\text { STEC / VTEC } \approx \frac{\left(h_{m}+R_{E}\right)}{\sqrt{\left(h_{m}+R_{E}\right)^{2}-\left(R_{h}+R_{E}\right)^{2} \cos ^{2} \beta}}
$$

where $h_{m}$ is the height of maximum electron density (varies between $250-450 \mathrm{~km}$ ), $R_{E}$ is the earth's mean radius ( $6371 \mathrm{~km}), R_{h}$ is the receiver height above the earth's surface and $\beta$ is the elevation angle.

Based on similar techniques using observation from more than hundred worldwide GNSS ground stations, German Aerospace Center (DLR) Neustrelitz computes vertical TEC estimates at numerous IPPs worldwide. Thus, TEC maps are produced by assigning IPP measurements to homogeneous latitude and longitude grid points as shown in Fig. 1 . European and global TEC maps and 1-hour-ahead forecasts are distributed via the operational space-weather and ionosphere data service SWACI (Space Weather Application Center Ionosphere, http://swaciweb.dlr.de, see also Jakowski et al., 2011) to the international community with an update rate of 5 minutes. The advantage of such services is that single frequency GNSS users can correct the ionospheric propagation effect in near real time.

\section{Estimation of ionospheric effects}

\subsection{First- and higher-order ionospheric terms}

Equations (12) and (13) indicate that the signal delay caused by the first order term is equal in magnitude but opposite in sign on GNSS carrier-phase and code pseudoranges, i.e., the carrier-phase pseudorange is advanced while code pseudorange is retarded. The first order term is directly proportional to the TEC encountered by the satellite signal during its travel through the ionosphere and inversely proportional to the square of the signal frequency. The first order term includes about $99 \%$ of the total ionospheric effect. Therefore, if the frequency and link related slant TEC are known, the first order propagation effect can easily be computed and corrected. If the TEC map is available, the slant TEC can be computed simply multiplying the vertical TEC at the IPP by the mapping function (e.g., Eq. 29). 
The vertical TEC may vary between 1 TECU and 300 TECU depending on a number of factors such as local time, geographic location, season, solar activity level etc. The frequency dependence of the first order ionospheric term has been plotted for elevations $5^{\circ}$ and $30^{\circ}$ in Fig. 2 at different levels of ionospheric ionization characterized by vertical TECs such as i) 250 and 150 TECU correspond to TEC during extreme space weather conditions, ii) 50 TECU corresponds to mid latitude day time and iii) 5 TECU corresponds to mid latitude night time TEC.
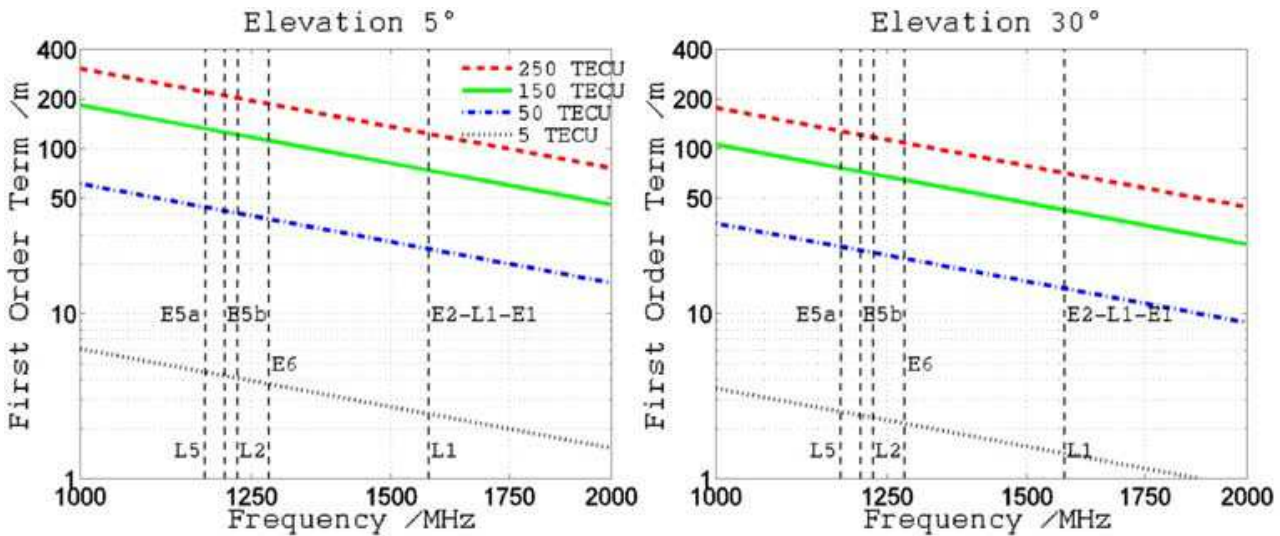

Fig. 2. Frequency dependence of the first order term at different levels of ionospheric ionization and elevation angles.

As Fig. 2 demonstrates, the first order ionospheric term can be more than $100 \mathrm{~m}$ at GNSS L-band frequencies $(1-2 \mathrm{GHz})$ during times of high TEC at low elevation angles.

\subsubsection{Second order term}

Higher order ionospheric terms include the second and third order ionospheric terms, and the excess path length. Equations $(5,6,8)$ indicate that the second order term depends on the electron density $n_{e}$ and as well as on the geomagnetic induction $B$. The electron gyro frequency $f_{g}=e B /(2 \pi m)$ is usually less than $1.4 \mathrm{MHz}$. The value of $B$ can be derived as $\sim 5 \times 10^{-5}$ Tesla for $f_{g}=1.4 \mathrm{MHz}$ and considered constant throughout the propagation. Thus, for the worst case condition with $f_{g}=1.4 \mathrm{MHz}$ and $\Theta=0$, the second order term can be simplified as (using Eqs. 5 and 8)

$$
d_{\text {Igr }}^{(2)}=\frac{11.28 \times 10^{7}}{f^{3}} \text { TEC }
$$

where $d_{I g r}^{(2)}$ is measured in meters, TEC in electrons $/ \mathrm{m}^{2}$ and $f$ in Hz. Using the above approximation, the frequency dependence of the second order term at different levels of ionospheric ionization and elevation angles has been plotted in Fig. 3.

Figure 3 shows that during the worst case conditions the second order ionospheric term on code observables can be as big as about 500 millimeters at GNSS L-band frequencies. Due to 
the dependency on $B$ field, the second order term depends on the receiver's geographic / geomagnetic position and direction of the signal reception. Such dependencies are given in Fig. 4. The simulation has been made using a two dimensional ray tracing program (Hoque \& Jakowski, 2008) which includes International Geomagnetic Reference Field (IGRF) (Mandea \& Macmillan, 2000) model for magnetic field computation along ray paths. A single layered Chapman profile (Eq. 40, see Rishbeth \& Garriott, 1969) with a maximum ionization of $4.96 \times 10^{12} \mathrm{~m}^{-3}$ at $350 \mathrm{~km}$ altitude and atmospheric scale height of $70 \mathrm{~km}$ has been used, and the corresponding vertical TEC is found 143 TECU.
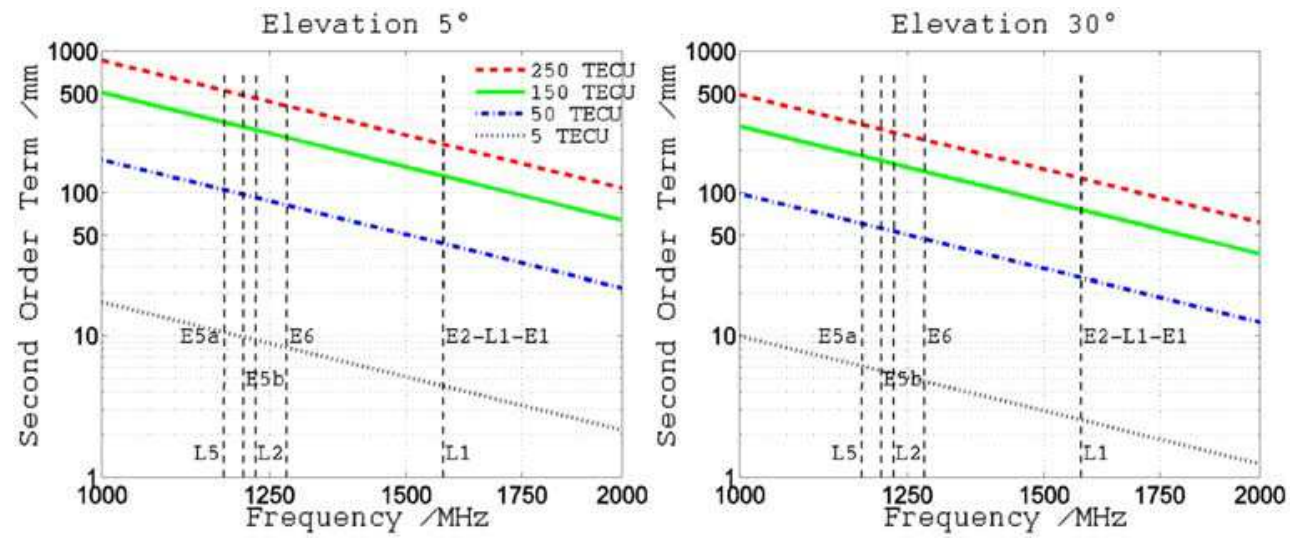

Fig. 3. Frequency dependence of the second order term $d_{I g r}^{(2)}$ at different levels of ionospheric ionization and elevation angles

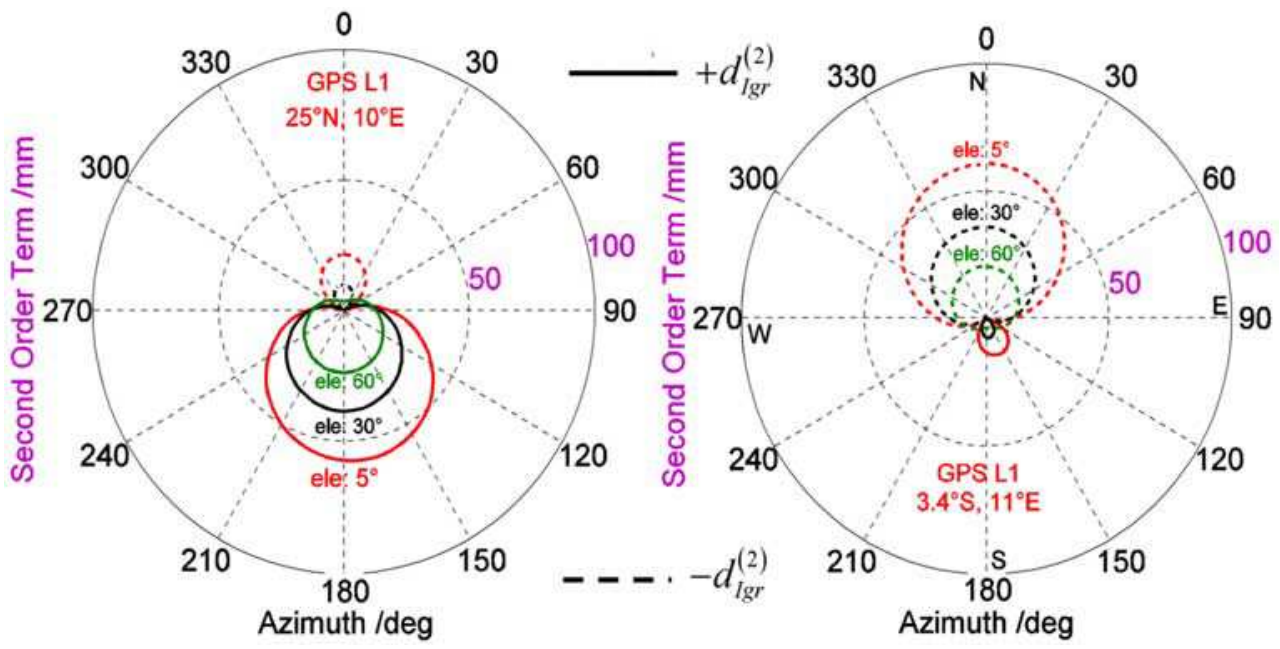

Fig. 4. Azimuth dependency of the second order term at GPS L1 frequency for elevations $5^{\circ}$, $30^{\circ}$ and $60^{\circ}$ and VTEC $=143$ TECU. The receiver position is considered at geographic $25^{\circ} \mathrm{N}$, $10^{\circ} \mathrm{E}$ and at its geomagnetic conjugate position $3.4^{\circ} \mathrm{S}, 11^{\circ} \mathrm{E}$. The symbols $\mathrm{N}, \mathrm{E}, \mathrm{S}$ and $\mathrm{W}$ correspond to the geographic north, east, south and west directions, respectively 
For a GNSS user in the northern hemisphere the magnitude of the second order term is the largest when the signal is received from a satellite in southward direction. However, for a user in the southern hemisphere the scenario is reversed, i.e., the largest effect is observed when the signal is received from a satellite in northward direction. Figure 4 shows that the magnitude of the second order term and its sign differ depending on the user location on the earth and direction of the signal reception. Therefore, such non systematic effects cannot be cancelled out by averaging GNSS measurements over long period at a certain user location.

\subsubsection{Third order term}

The third order term depends on the integral $\int n_{e}^{2} d s$ (see Eq. 9) which can be simplified as $0.6577 N_{m}$ TEC (obtained by analytical integration of the Chapman layer, Hoque \& Jakowski, 2008, see also Brunner \& Gu, 1991; Hartmann \& Leitinger, 1984; Leitinger \& Putz, 1988) where $N_{m}$ is the maximum ionospheric ionization. Therefore, assuming the worst case condition with $f_{g}=1.4 \mathrm{MHz}$ and $\Theta=0$, the third order term can be simplified as (using Eqs. 5 and 9)

$$
d_{\text {Igr }}^{(3)}=\left(1602.81 N_{m}+2.37 \times 10^{14}\right) \frac{T E C}{f^{4}}
$$

where $d_{I g r}^{(3)}$ is measured in meters, TEC is the slant TEC and measured in electrons $/ \mathrm{m}^{2}, f$ in $\mathrm{Hz}$ and $N_{m}$ is measured in $\mathrm{m}^{-3}$. If the vertical TEC is known, $N_{m}$ can be computed assuming a Chapman profile for the ionosphere by the following expression (Hoque \& Jakowski, 2007).

$$
V T E C=4.13 H N_{m}
$$

where VTEC is the TEC in vertical direction and $H$ is the atmospheric scale height. The parameter $H$ can be assumed as $70 \mathrm{~km}$ for a rough estimation of the third order ionospheric term. Using the above approximations (Eqs. 31 and 32) the frequency dependence of the third order term at different levels of ionospheric ionization and elevation angles has been plotted in Fig. 5.
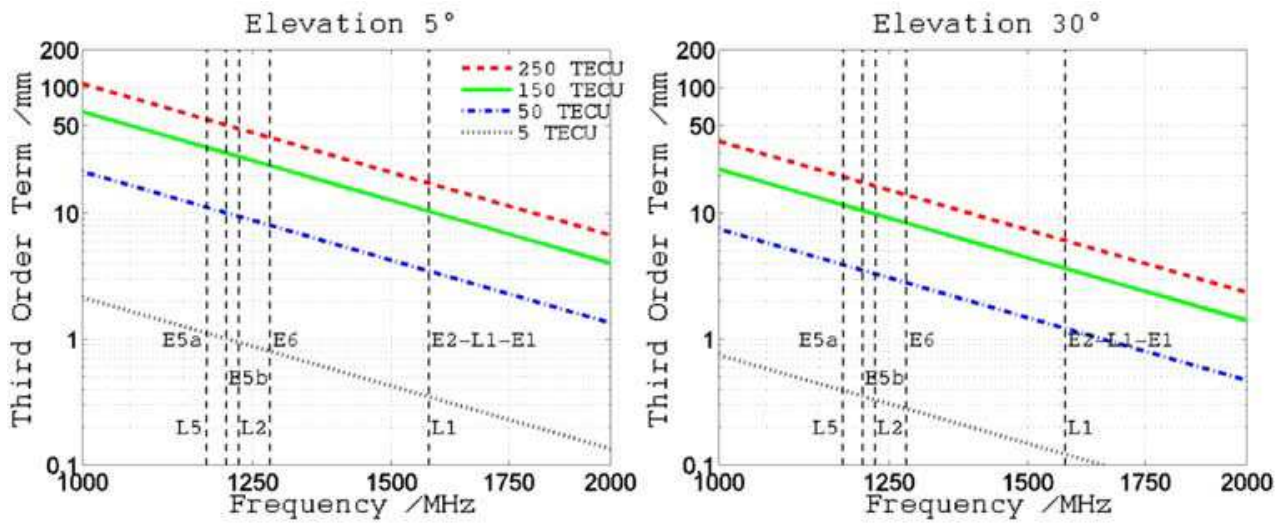

Fig. 5. Frequency dependence of the third order term $d_{I g r}^{(3)}$ at different levels of ionospheric ionization and elevation angles 
Figure 5 shows that the third order term on code observables can be as big as $50 \mathrm{~mm}$ at low elevation angles during times of high TEC.

\subsection{Estimate of LoS propagation assumption error}

Due to the ray path bending satellite signals propagate through curvature paths instead of straight line of sight paths. However, a curvature path length and the corresponding LoS path length are not equal rather the curvature path is slightly longer than the LoS one. The difference between them is defined as the excess path length and it can be computed by the following formula given by Jakowski et al. (1994).

$$
d_{I}^{\text {len }}=\frac{b_{1}}{f^{4}}\left(\frac{1}{\left(1-b_{2} \cos ^{2} \beta\right)^{1 / 2}}-1\right) \operatorname{TEC}^{2}
$$

where $b_{1}=2.495 \times 10^{8}, b_{2}=0.8592$ and $\beta$ is the elevation angle. The excess path length $d_{I}^{\text {len }}$ will be estimated in millimeters when $\beta$ is measured in radians, $f$ is in MHz and TEC is in TEC units. The frequency dependence of the excess path length has been plotted in Fig. 6 .
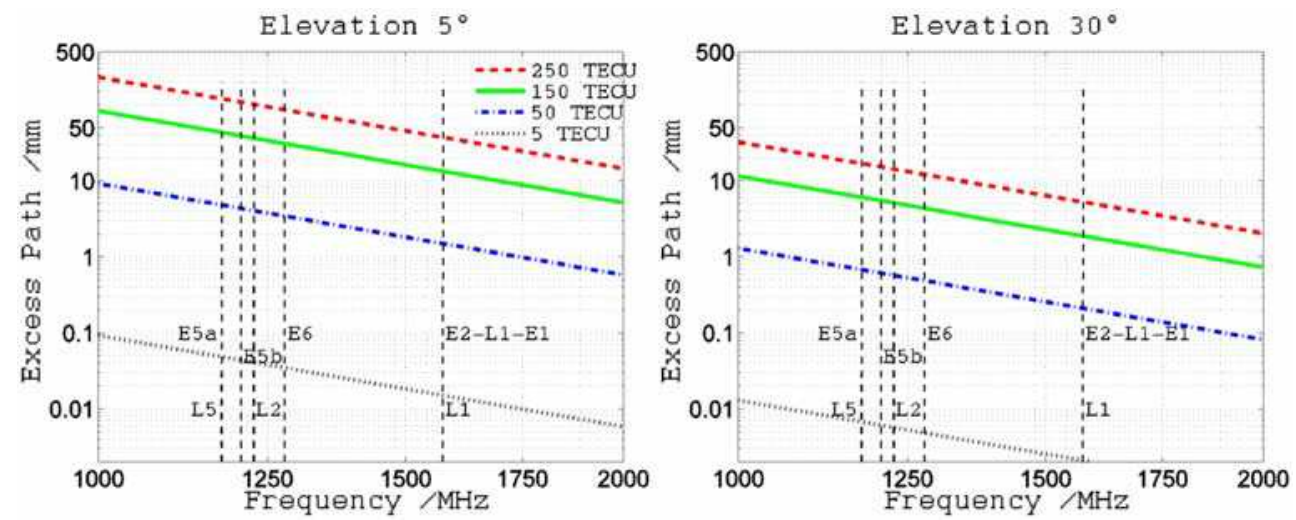

Fig. 6. Frequency dependence of the excess path length at different levels of ionospheric ionization and elevation angles

Figure 6 shows that at the L2 frequency, the excess path length can be as big as $100 \mathrm{~mm}$ at low elevation angles during times of high TEC such as VTEC $=250 \mathrm{TECU}$.

\subsection{Estimates of residual terms in the ionosphere-free solution}

Although residual terms in ionosphere-free solutions are less than $1 \%$ of the first order ionospheric effect, they cannot be ignored if centimeter / millimeter level accuracy is required in GNSS positioning and timing applications. A plot showing comparison of dualfrequency GPS L1-L2 residual terms is given in Fig. 7 for better understanding of their relative influences on precise range estimation. For this, the ray tracing tool has been used in which the ionosphere is modelled by a Chapman layer with a peak density of $7.75 \times 10^{12} \mathrm{~m}^{-3}$ at $350 \mathrm{~km}$ altitude and scale height of $78 \mathrm{~km}$, and corresponding VTEC $=250 \mathrm{TECU}$. 
We see that at low elevation angle $\left(<15^{\circ}\right), \Delta s_{T E C}$ is the largest and it decreases very rapidly with increasing the elevation angle. The second order term $\Delta s_{2}$ is determined for an azimuth angle $180^{\circ}$ at a receiver position at geographic $50^{\circ} \mathrm{N}$ and $15^{\circ} \mathrm{E}$. Although $\Delta s_{2}$ is less than the $\Delta s_{T E C}$ at low elevation angles, it exceeds $\Delta s_{T E C}$ at higher elevation angles $\left(>25^{\circ}\right)$. The $\Delta s_{2}$ does not reduce significantly with increasing the elevation angle and therefore, it cannot be ignored even at zenith. The excess path length $\Delta s_{\text {len }}$ decreases with increasing the elevation angle very rapidly and vanishes at zenith. The third order term $\Delta s_{3}$ is small $(<5 \mathrm{~mm})$ but it can be bigger than $\Delta s_{T E C}$ and $\Delta s_{\text {len }}$ at very high $\left(>60^{\circ}\right)$ elevation angles. We find that the magnitude of the RRE $E_{\text {gr }}$ is much higher than the RRE. This is mainly due to different signs of $\Delta s_{T E C}$ and $\Delta s_{\text {len }}$ in the RRE and RRE $E_{\text {gr }}$ expressions. In case of the code combination Eq. (14), $\Delta s_{\text {len }}$ is additive to other terms whereas it is subtractive in the carrier-phase combination Eq. (15). Additionally, the $\Delta s_{2}$ and $\Delta s_{3}$ are two and three times higher in the code combination compared to the phase combination.

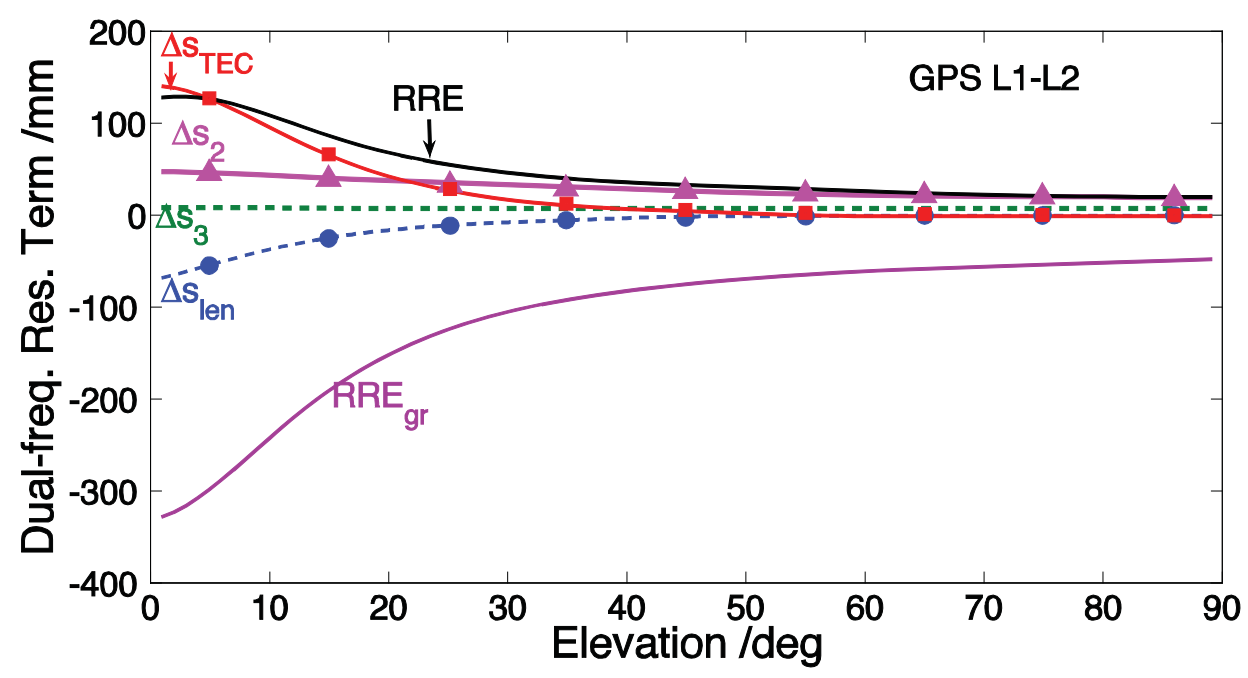

Fig. 7. Residual terms in the dual-frequency GPS L1-L2 combination for an ionospheric ionization of $\mathrm{VTEC}=250 \mathrm{TEC}$ units

For the same ionospheric ionization, the residual terms in the triple-frequency GPS L1-L2-L5 combination (Eqs. 21-22) are plotted in Fig. 8. It shows that the magnitude of $\left(R_{R E}\right)_{\text {gr }}$ is much higher than the magnitude of (RRE) tr. The reason is already discussed for the dualfrequency case.

We find that the GPS L1-L2 residual terms $\Delta s_{3}, \Delta s_{T E C}$ and $\Delta s_{\text {len }}$ are about 2.4 times higher than the GPS L1-L2-L5 residual terms $\left(\Delta s_{3}\right)_{t r},\left(\Delta s_{T E C}\right)_{t r}$ and $\Delta s_{\text {len }}$. The sum of all residual terms, i.e., $R R E$ and $R R E_{g r}$ are found to be more than three times higher for the L1-L2 combination than the L1-L2-L5 combination.

Comparing the dual- and triple-frequency carrier-phase combinations Eq. (15) and Eq. (22), we see that the signs of $\Delta s_{T E C}$ and $\Delta s_{3}$ are positive in the dual-frequency combination whereas their signs are negative in the triple-frequency combination. However, the sign of 
$\Delta s_{\text {len }}$ is negative in the dual-frequency combination and positive in the triple-frequency combination. Again, the magnitude of $\Delta s_{T E C}$ is higher than the magnitude of $\Delta s_{\text {len }}$ for both combinations. As a result, the triple-frequency (RRE) tr $_{\text {is }}$ found to be negative, i.e., the corrected $\rho$ is longer than the uncorrected one whereas the dual-frequency RRE is found to be positive, i.e., the corrected $\rho$ is shorter than the uncorrected $\rho$. Similarly, it can be shown that $\left(R R E_{g r}\right)_{t r}$ is positive in the triple-frequency combination and $R R E_{g r}$ is negative in the dual-frequency combination. These relations are true for combination frequencies $f_{1}>f_{2}>f_{3}$.

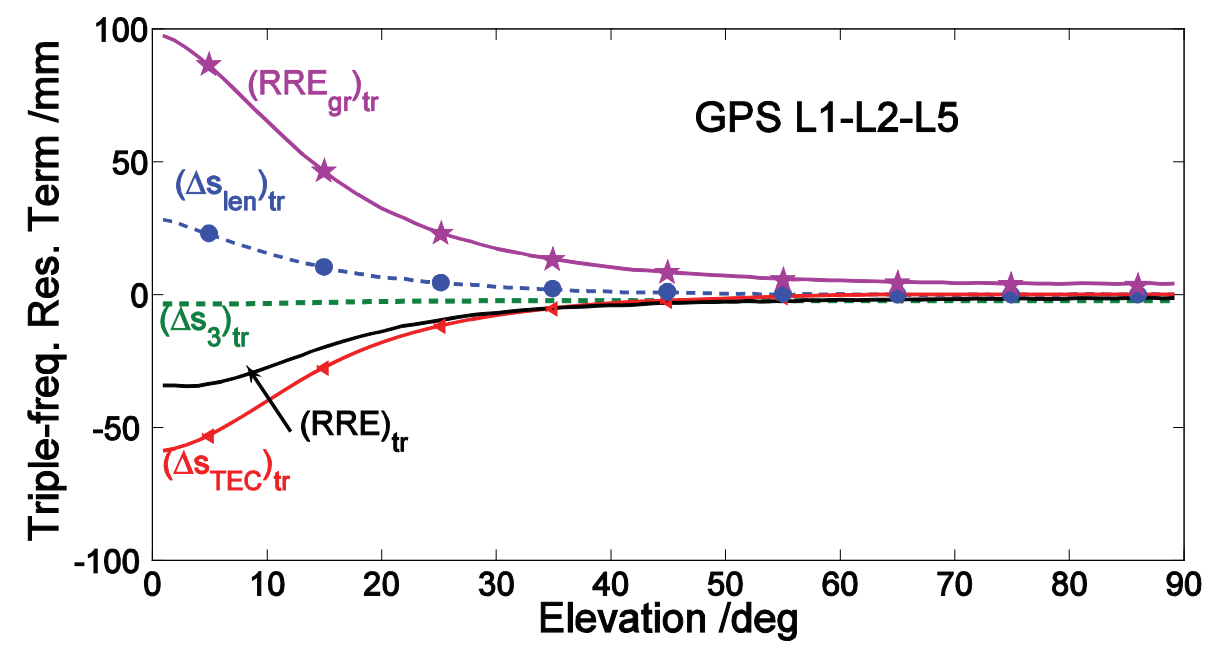

Fig. 8. Residual terms in the triple-frequency GPS L1-L2-L5 combination for an ionospheric ionization of $\mathrm{VTEC}=250$ TEC units

\section{Correction of higher order ionospheric terms}

\subsection{Second order term correction}

The estimation of the second order term requires computation of the geomagnetic induction and its direction with respect to the propagation direction along ray paths. Since this computation is very cumbersome, a common practice is to assume the ionosphere as a single thin layer at a certain altitude and compute $B \cos \Theta$ at the IPP and consider it constant throughout the propagation. Thus, the second order term coefficient $q$ (Eq. 8) can be written as

$$
q \approx 2.2566 \times 10^{12} B^{*} \cos \Theta^{*} T E C
$$

where TEC is the total electron content along ray paths, $B^{*}$ is the magnitude of $B$, and $\Theta^{*}$ is the angle between the magnetic field vector and the wave direction at the IPP (the symbol * denotes the values at the single layer).

Bassiri and Hajj (1993) were the first to propose such a single thin layered ionosphere for the second order ionospheric correction; they choose the $300 \mathrm{~km}$ as a representative global 
average peak height. Later Kedar et al. (2003) assumed the ionosphere as a single layer at a $400 \mathrm{~km}$ altitude for estimating the effect of the second order GPS ionospheric correction on receiver positions. Hernandez-Pajares et al. (2007) considered the ionosphere as a single

layer at a $450 \mathrm{~km}$ altitude to estimate the impact of the second order ionospheric term on geodetic estimates.

The computation of $B \cos \Theta$ along ray paths requires the knowledge of the ionospheric profile shape which is not available to the GNSS users; they only have TEC information along ray paths. Therefore, assumptions of a thin ionospheric layer and $B \cos \Theta$ computation at the IPP are very suitable for practical use. However, such assumptions lead up to $2 \mathrm{~mm}$ errors in the second order ionospheric term computation (Hoque \& Jakowski, 2008).

As an alternative approach, we (Hoque \& Jakowski, 2007) assume an average value $\overline{B \cos \Theta}$ for the magnetic field component and consider it constant throughout the propagation. Based on simulation studies we derived a correction formula for the $\overline{B \cos \Theta}$ computation along any receiver-to-satellite link geometries inside European geographic latitude $30-65^{\circ}$ $\mathrm{N}$ and longitude $15^{\circ} \mathrm{W}-45^{\circ} \mathrm{E}$.

$$
\Delta s_{2}=\frac{1.1283 \times 10^{12}}{f_{1} f_{2}\left(f_{1}+f_{2}\right)} \cdot \overline{B \cos \Theta} \cdot \text { TEC }
$$

In which

$$
\begin{aligned}
\overline{B \cos \Theta}=-y_{1} \cos \alpha & +\left|\sqrt{r_{1}^{2}-y_{1}^{2} \sin ^{2} \alpha}\right|-2 r_{2} \cos \alpha^{\prime} \\
r_{1} & =\varsigma\left(\beta, \phi, \lambda, a_{i}\right) \\
r_{2} & =\varsigma\left(\beta, \phi, b_{i}\right) \\
y_{1} & =\varsigma\left(\beta, \phi, c_{i}\right)
\end{aligned}
$$

The parameters $r_{1}, r_{2}$ and $y_{1}$ are the functions of the receiver-to-satellite elevation angle $\beta$, geographic latitude $\varphi$ and longitude $\lambda$ at the receiver position. The quantity $\alpha$ is the receiverto-satellite azimuth angle and $\alpha^{\prime}$ is the modified azimuth angle. The quantities $a_{i}, b_{i}$ and $c_{i}$ are the polynomial coefficients. Thirty polynomial coefficients have been derived for the European region $\left(30^{\circ}-65^{\circ} \mathrm{N}, 15^{\circ} \mathrm{W}-45^{\circ} \mathrm{E}\right)$ by least squares fitting of ray tracing results. Inside the ray tracing program, the IGRF model has been used to compute $B \cos \Theta$ along ray paths. For details and values of the polynomial coefficients we refer to Hoque \& Jakowski (2007). Using such a correction formula and knowing the TEC value, the second order term can be corrected to the 2-3 millimeter accuracy level for a vertical TEC level of 100 TEC units. The formula can be adapted for other geographic regions too after deriving new set of polynomial coefficients.

\subsection{Third order term correction}

It has been found that the second term of Eq. (9) is less than the first term by about 1-2 orders of magnitude. As already discussed in the section 3.1.2, the integral $\int n_{e}^{2} d s$ can be 
simplified as $0.6577 N_{m} T E C$. Thus, the third order residual term can be approximated by the first term only as (using Eqs. 9 and 19)

$$
\Delta s_{3}=\frac{534.27}{f_{1}^{2} f_{2}^{2}} N_{m} T E C
$$

The third order term $\Delta s_{3}$ will be measured in meters when $f$ is measured in $\mathrm{Hz}$ and the maximum ionization $N_{m}$ and TEC in $\mathrm{m}^{-3}$ and electrons $/ \mathrm{m}^{2}$, respectively.

\subsection{New approaches for correcting LoS propagation assumption errors}

\subsubsection{Excess path length correction}

As we have seen in the section 3.2, the excess path length $d_{I}$ len can be computed by Eq. (33). There is another formula published by Hoque \& Jakowski (2008) for the excess path length computation.

$$
d_{I}^{\text {len }}=\frac{7.5 \times 10^{-5} \exp (-2.13 \beta) T E C^{2}}{f^{4} H(h m)^{1 / 8}}
$$

where $d_{l}{ }^{\text {len }}$ is measured in meters, TEC is in TEC units, frequency $f$ in GHz, atmospheric scale height $H$ and maximum ionization height $h m$ in kilometers and elevation $\beta$ in radians. Comparing both formulas we see that Eq. (33) requires only TEC and elevation information as inputs whereas Eq. (39) additionally requires ionospheric parameters $H$ and $\mathrm{hm}$. However, these parameters are not easy to estimate in practical cases.

Both the correction formulas are derived based on simulation studies using Chapman profiles for the ionosphere. The Chapman profile (Rishbeth \& Garriott, 1969) has been proved very useful for modeling ionospheric correction. It describes the electron density distribution $n_{e}$ as a function of height $h$ in the ionosphere as

$$
n_{e}(h)=N m \exp (0.5(1-z-\exp (-z)))
$$

where $N m$ is the maximum ionization and $z=(h-h m) / H$ in which $h m$ is the height of maximum ionization and $H$ is the atmospheric scale height.

We have found that the correction by Eq. (33) shows the best performance for the atmospheric scale height $H=70 \mathrm{~km}$. However, when the scale height is too low (e.g., $H=60$ $\mathrm{km}$ ) or too large (e.g., $H=80 \mathrm{~km}$ ), its performance degrades especially at low elevation angles (see Fig. 9). Our present investigation shows that its performance can be improved by taking into account the $d_{l}^{\text {len }}$ dependency on the rate of change of TEC with respect to the elevation angle. In order to find their dependencies, the excess path length has been computed by the ray tracing program considering Chapman profiles with different $H=60$ and $80 \mathrm{~km}$. The signal frequency $f=1227.6 \mathrm{MHz}$, parameters $h m=350 \mathrm{~km}$ and $\mathrm{Nm}=$ $4.96 \times 10^{12} \mathrm{~m}^{-3}$ are kept constant in each case. The total electron content in the vertical direction is found 123 and 164 TEC units, respectively. The obtained dlen, TEC, and the first and second order TEC derivatives with respect to the elevation angle $d T E C / d \beta$ and 
$d^{2}$ TEC/ $d \beta^{2}$ have been plotted as functions of elevation angle in Fig. 9. The $d T E C / d \beta$ has been calculated dividing the TEC difference between two measurement epochs by the corresponding elevation angle difference. Then, $d^{2} T E C / d \beta^{2}$ has been calculated dividing the $d T E C / d \beta$ difference between two measurement epochs by the corresponding elevation angle difference.

Comparing plots in Fig. 9, we see that although the dependency of $d^{l e n}$ on the $d T E C / d \beta$ is not straight forward, its dependency on the $d^{2} T E C / d \beta^{2}$ is obvious at low elevation angles $\left(<20^{\circ}\right)$. Thus, the magnitude of the dlen depends on the magnitude of TEC as well as on the magnitude of $d^{2} T E C / d \beta^{2}$. Considering this, functional dependencies have been studied separately for different parameters to develop correction formulas. For this, ray tracing calculation has been carried out for different geometrical and ionospheric conditions varying elevation and Chapman layer parameters $H, N m$ and $h m$. Thus, the following formula has been obtained for the $d_{l}^{\text {len }}$ correction.
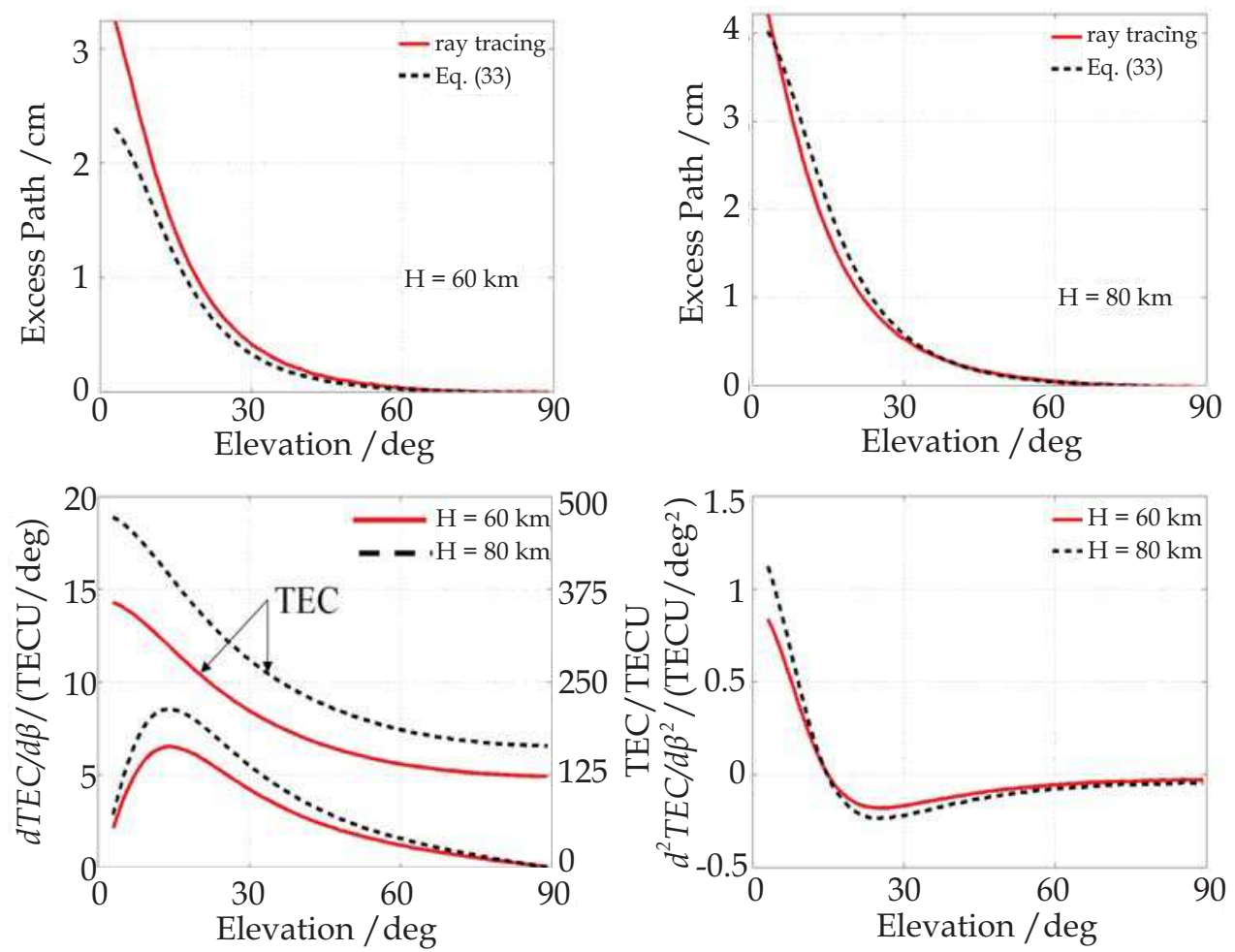

Fig. 9. Elevation angle dependence of $d_{l}$ len, TEC (see right scale), $d T E C / d \beta$ and $d^{2} T E C / d \beta^{2}$ for the Chapman layer parameter $H=60$ and $80 \mathrm{~km}$

$$
d_{I}^{\text {len }}=\frac{a_{1}}{f^{4}}\left(\frac{1}{\left(1-a_{2} \cos ^{2} \beta\right)^{1 / 2}}-1\right) \operatorname{TEC}^{2}+a_{3}\left(\frac{d^{2} \mathrm{TEC}}{d \beta^{2}}\right)^{2} \cos \beta
$$


where $a_{1}=2.6123 \times 10^{8}, a_{2}=0.8260, a_{3}=6.64$. The $d_{l}$ len will be computed in millimeters when $\beta$ is measured in radians, $f$ is in MHz, TEC is in TEC units and $d^{2}$ TEC/ $d \beta^{2}$ in TECU/deg2. The polynomial coefficients are derived based on a nonlinear fit with ray tracing results in least square senses.

The elevation angle dependence of $d_{l}$ len has been plotted in Fig. 10 using the proposed correction formula Eq. (41) as well as by Eqs. (33) and (39). In addition, ray tracing results are plotted for comparisons. Comparing $d_{l}$ len computed by the Eq. (33) and Eq. (41) with ray tracing results, we see that at higher $H$ values (e.g., $H=80 \mathrm{~km}$ ) the correction given by the Eq. (41) performs better. However, its performance degrades at lower $H$ values (e.g., $H=60$ $\mathrm{km})$, especially around $7-21^{\circ}$ elevation angle.

We find that the Eq. (39) gives the best performance. However, it requires ionospheric parameters $H$ and $\mathrm{hm}$ as inputs which are not known to the GNSS users. Inaccurate assumption of ionospheric parameters may give erroneous estimation of $d_{l}{ }^{\text {len }}$. We see that at $H=80 \mathrm{~km}$ the correction given by the new approach Eq. (41) is even comparable to the correction given by Eq. (39).
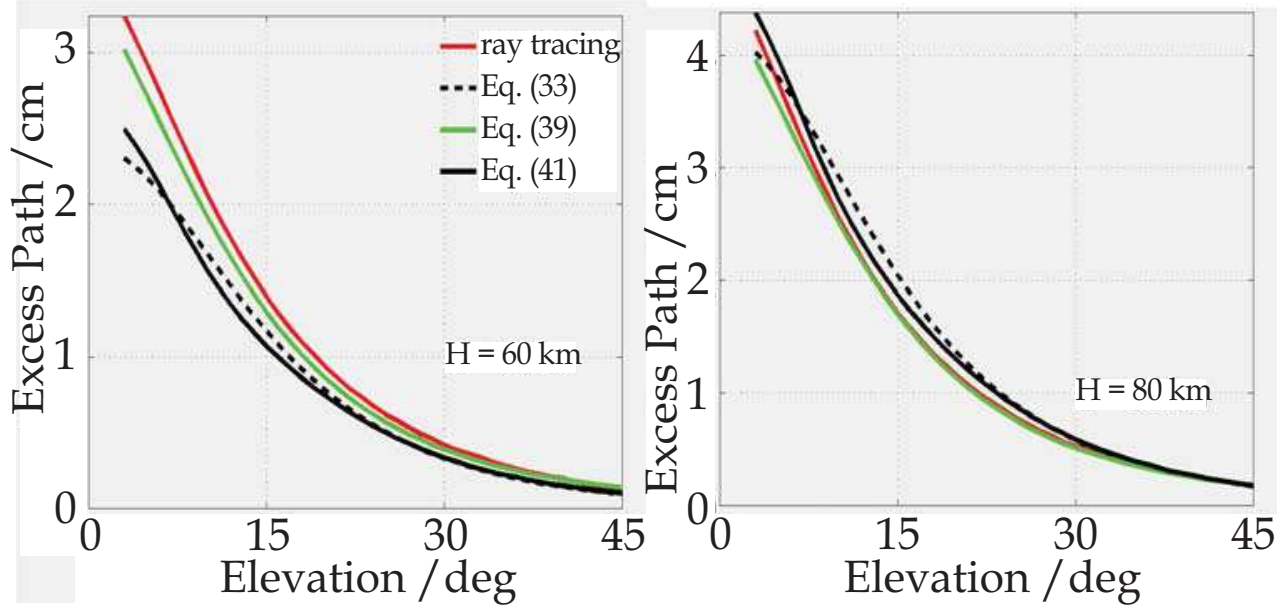

Fig. 10. Comparison of excess path length correction formulas with ray tracing results

While using the proposed correction Eq. (41), it should be remembered that due to its dependency on the $d^{2} T E C / d \beta^{2}$ term, it is very sensitive to TEC gradients or irregularities. In such cases the correction given by Eq. (33) is recommended for use.

\subsection{2 $\triangle \mathrm{TEC}_{\text {bend }}$ correction}

Due to the ray path bending satellite signals propagate in curvature paths instead of straight LoS paths. However, TECs along a curvature path and the corresponding LoS path are not the same rather the TEC along the curvature path is slightly larger than the LoS one. The difference between them is defined as the $\triangle T E C_{\text {bend }}$ (see Eq. 7). The $\triangle T E C_{\text {bend }}$ can be computed by the following formula given by Hoque \& Jakowski (2008). 


$$
\Delta \mathrm{TEC}_{\text {bend }}=\frac{1.108 \times 10^{-3} \exp (-2.1844 \beta) T E C^{2}}{f^{2} H h m^{0.3}}
$$

where $\triangle T E C_{\text {bend }}$ is measured in TECU, atmospheric scale height $H$ is in $\mathrm{km}$, the maximum ionization height $h m$ is in $\mathrm{km}$, signal frequency $f$ is in GHz, TEC is in TECU and elevation angle $\beta$ is in radians. Again, it requires the knowledge of the ionospheric parameters $H$ and $\mathrm{hm}$. If actual parameters are not known, the formula may not be useful in practical purposes. Therefore, in the present work, we have looked for a correction formula depending only on the TEC, elevation angle and second order derivative of TEC with respect to the elevation. We have found that the formula Eq. (41) can be used for such purposes multiplying simply by $f^{2}$ and determining new coefficients.

$$
\Delta T E C_{\text {bend }}=\frac{c_{1}}{f^{2}}\left(\frac{1}{\left(1-c_{2} \cos ^{2} \beta\right)^{1 / 2}}-1\right) T E C^{2}+c_{3}\left(\frac{d^{2} T E C}{d \beta^{2}}\right)^{2} \cos \beta
$$

where $c_{1}=1.2963, c_{2}=0.8260, c_{3}=0.0496$. The $\triangle T E C_{b e n d}$ will be computed in TEC units when $\beta$ is measured in radians, $f$ is in MHz and TEC is in TEC units and $d^{2}$ TEC/ $d \beta^{2}$ in TECU/deg 2 . The polynomial coefficients are derived based on a nonlinear fit with ray tracing results in least square senses as before.
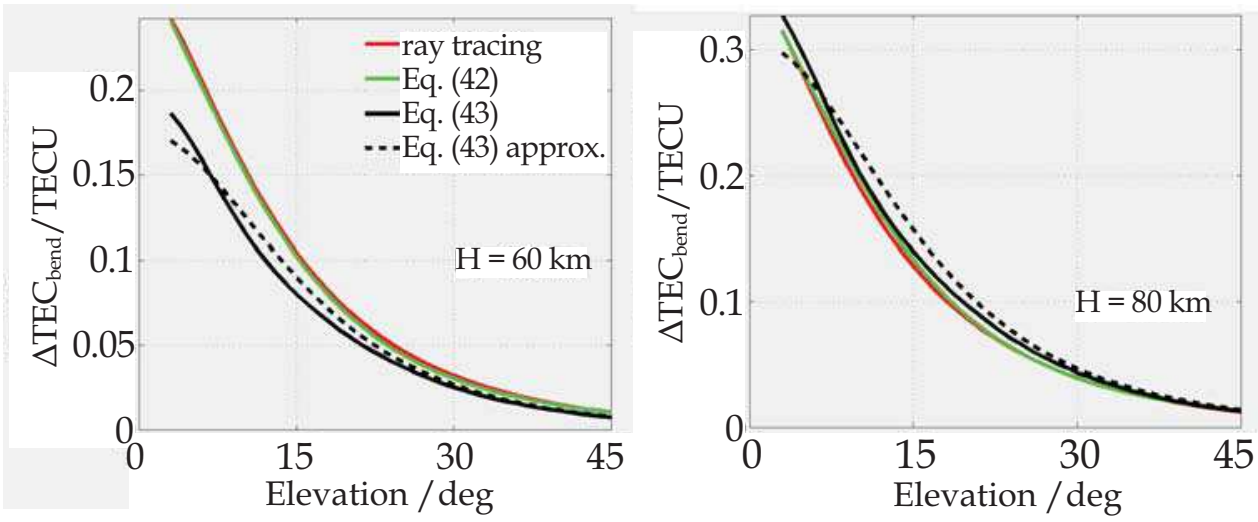

Fig. 11. Comparison of $\triangle T E C_{\text {bend }}$ correction formulas with ray tracing results

The elevation angle dependence of $\triangle T E C_{\text {bend }}$ has been plotted in Fig. 11 for the proposed correction formula Eq. (43) as well as for the Eq. (42). Also ray tracing results are plotted for comparisons. Comparing $\triangle T E C_{\text {bend }}$ computed by the Eq. (43) and Eq. (42) with ray tracing results, we see that at higher $H$ values (e.g., $H=80 \mathrm{~km}$ ) both correction results are comparable. However, the performance of the new approach significantly degrades at lower $H$ values (e.g., $H=60 \mathrm{~km}$ ).

As already mentioned, the derivative $d^{2} T E C / d \beta^{2}$ is very sensitive to TEC gradients. Considering this, another set of coefficients have been determined excluding the derivative term in Eq. (43). In this case, we have found that $c_{1}=1.4563, c_{2}=0.8260$ and $c_{3}$ is set to zero. 
The elevation angle dependency for such an approximation of Eq. (43) is also plotted in Fig. 11.

As already mentioned, after removal of the Selective Availability, the ionosphere becomes the single largest error source for GNSS error budgets. Fortunately, a dual-frequency ionosphere-free combination can remove about $99 \%$ of the ionospheric effects; thanks to the dispersive nature of the ionosphere. Although higher order residual terms are less than $1 \%$ of the first order term, they can be many centimeters during times of high TEC and represent large errors in geodetic measurements especially in precise point positioning. This chapter gives estimation of higher order ionospheric terms at different level of ionospheric ionization and discusses different correction approaches for them.

\section{References}

Appleton, E. V. (1932). Wireless studies of the ionosphere, Proceeding of Instn. Elect. Engrs., Vol. 7, No. 21, pp. (257-265), 10.1049/pws.1932.0027

Bassiri, S. \& Hajj, G. A. (1993). Higher-order ionospheric effects on the global positioning system observables and means of modeling them. manuscripta geodaetica, Vol. 18, No. 6, pp. (280-289)

Blewitt, G. (1987). New approaches to GPS carrier-phase ambiguity resolution. Proceeding of XIX General Assembly of the IUGG, Vancouver, Canada, August 10-22

Brunner, F. K. \& Gu, M. (1991). An improved model for the dual frequency ionospheric correction of GPS observations. manuscripta geodaetica, Vol. 16, No. 3, pp. (205214)

Budden, K. G. (Ed.). (1985). The Propagation of Radio Waves: the theory of radio waves of low power in the ionosphere and magnetosphere, Cambridge University Press, Cambridge.

Datta-Barua, S., Walter, T., Blanch, J. \& Enge, P. (2008). Bounding higher-order ionosphere errors for the dual-frequency GPS user. Radio Sci., Vol. 43, No. RS5010, pp. (15), doi:10.1029/2007RS003772

Davies, K. (Ed.). (1990). Ionospheric Radio, Peter Peregrinus Ltd, London.

Elizabeth, J. P., Matt, A. K., Philip, M. \& David, A. L. (2010). A first look at the effects of ionospheric signal bending on a globally processed GPS network. J Geod, Vol. 84, pp. (491-499), DOI 10.1007/s00190-010-0386-2

Fritsche, M., Dietrich, R., Knöfel, C., Rülke, A., Vey, S., Rothacher, M. \& Steigenberger, P. (2005). Impact of higher-order ionospheric terms on GPS estimates. Geophys Res Lett, Vol. 32, No. 23, L23311, DOI 10.1029/2005GL024342

Hartmann, G. K. \& Leitinger, R. (1984). Range errors due to ionospheric and tropospheric effects for signal frequencies above $100 \mathrm{MHz}$. Bull. Geod, Vol 58, No. 2, pp. (109136)

Hawarey, M., Hobiger, T. \& Schuh, H. (2005). Effects of the 2nd order ionospheric terms on VLBI measurements. Geophys Res Lett, Vol. 32, No. 11, L11304, DOI 10.1029/2005GL022729

Hernandez-Pajares, M., Jaun, J. M., Sanz, J. \& Orus, R. (2007). Second order ionospheric term in GPS: implementation and impact on geodetic estimates. Journal of Geophysical Research, Vol. 112, No. B08417, doi:10.1029/2006JB004707 
Hoque, M. M. \& Jakowski, N. (2006). Higher-order ionospheric effects in precise GNSS positioning. Journal of Geodesy, Vol. 81, No. 4, pp. (259-268), DOI 10.1007/s00190006-0106-0

Hoque, M. M. \& Jakowski, N. (2007). Mitigation of higher order ionospheric effects on GNSS users in Europe. GPS Solut., Vol. 12, No. 2, doi: 10.1007/s10291-007-0069-5

Hoque, M. M. \& Jakowski, N. (2008). Estimate of higher order ionospheric errors in GNSS positioning, Radio Sci., Vol. 43, No. RS5008, doi: 10.1029/2007RS003817

Hoque, M. M. \& Jakowski, N. (2010a). Higher Order Ionospheric Errors in Modernized GPS and Future Galileo Systems. In: Global Positioning Systems, Asphaug V. \& Sorensen E. (Eds.), pp. (1-28), Nova Science Publishers, Inc., ISBN 978-1-60741012-6

Hoque, M. M. \& Jakowski, N. (2010b). Higher order ionospheric propagation effects on GPS radio occultation signals. J. Adv. Space Res., Vol. 46, No. 2, pp. (162-173), doi:10.1016/j.asr.2010.02.013

Hoque, M. M. \& Jakowski N. (2011). Ionospheric bending correction for GNSS radio occultation signals. Radio Sci, Vol. 46, No. RS0D06, pp. (9), doi:10.1029/2010RS004583

Jakowski, N., Porsch, F. \& Mayer, G. (1994). Ionosphere-Induced-Ray-Path Bending Effects in Precise Satellite Positioning Systems. Zeitschrift für Satellitengestützte Positionierung, Navigation und Kommunikation, Vol. SPN 1/94, pp. (6-13)

Jakowski, N., Mayer, C., Hoque, M. M. \& Wilken, V. (2011). TEC Models and Their Use in Ionosphere Monitoring. Radio Sci., doi:10.1029/2010RS004620

Kedar, S., Hajj, G., Wilson, B. \& Heflin, M. (2003). The effect of the second order GPS ionospheric correction on receiver positions. Geophys Res Lett, Vol. 30, No. 16, pp. (1829), DOI 10.1029/2003 GL017639

Kim, B. C. \& Tinin M. V. (2007). Contribution of ionospheric irregularities to the error of dual-frequency GNSS positioning. J Geod, Vol. 81, pp. (189-199), DOI 10.1007/s00190-006-0099-8

Kim, B.C. \& Tinin, M.V. (2011). Potentialities of multifrequency ionospheric correction in Global Navigation Satellite Systems. J Geodesy, Vol. 85, No. 3, pp. (159-169), doi: 10.1007/s00190-010-0425.

Klobuchar, J. A. (1996). Ionospheric Effects on GPS, In: Global Positioning System: Theory and Applications, Vol I, Parkinson, B. W. \& Spilker, J. J. (Eds.), pp. (485-515), American Institute of Aeronautics \& Astronautics, ISBN 156347106X

Leitinger R., Putz, E. (1988). Ionospheric refraction errors and observables, In: Atmospheric effects on the geodetic space measurements, Brunner, F. K. (Ed.), pp. (81-102), Monograph 12, School of Surveying, UNSW, Sydney

Mandea M. \& Macmillan, S. (2000). International Geomagnetic Reference Field - the eighth generation. Earth Planets Space, Vol. 52, No. 12, pp. (1119-1124)

Moore, R. C. \& Morton, Y.T. (2011). Magneto-ionic polarization and GPS signal propagation through the ionosphere, Radio Sci, Vol. 46, No. RS1008, doi: 10.1029/2010RS004380

Morton, Y. T., Zhou, Q. \& van Graas, F. (2009). Assessment of second-order ionosphere error in GPS range observables using Arecibo incoherent scatter radar measurements, Radio Sci., Vol. 44, No. RS1002, doi:10.1029/2008RS003888 
Parkinson, B. W. \& Gilbert, S. W. (1983). NAVSTAR: Global Positioning System - Ten Years Later. Proc IEEE, Vol. 71, No. 10, pp (1177-1186), 10.1109/PROC.1983.12745

Rishbeth, H. \& Garriott O. K. (Eds.). (1969). Introduction to ionospheric physics, Academic, New York

Strangeways, H. J. \& Ioannides, R. T. (2002). Rigorous calculation of ionospheric effects on GPS Earth-Satellite paths using a precise path determination methods. Acta Geod Geoph Hung, Vol. 37, No. 2-3, pp. (281-292) 


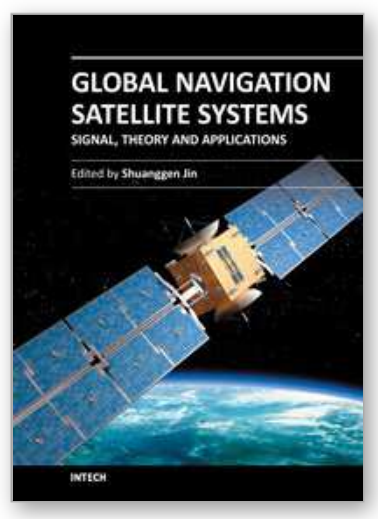

\author{
Global Navigation Satellite Systems: Signal, Theory and \\ Applications \\ Edited by Prof. Shuanggen Jin
}

ISBN 978-953-307-843-4

Hard cover, 426 pages

Publisher InTech

Published online 03, February, 2012

Published in print edition February, 2012

Global Navigation Satellite System (GNSS) plays a key role in high precision navigation, positioning, timing, and scientific questions related to precise positioning. This is a highly precise, continuous, all-weather, and real-time technique. The book is devoted to presenting recent results and developments in GNSS theory, system, signal, receiver, method, and errors sources, such as multipath effects and atmospheric delays. Furthermore, varied GNSS applications are demonstrated and evaluated in hybrid positioning, multi-sensor integration, height system, Network Real Time Kinematic (NRTK), wheeled robots, and status and engineering surveying. This book provides a good reference for GNSS designers, engineers, and scientists, as well as the user market.

\title{
How to reference
}

In order to correctly reference this scholarly work, feel free to copy and paste the following:

M. Mainul Hoque and Norbert Jakowski (2012). lonospheric Propagation Effects on GNSS Signals and New Correction Approaches, Global Navigation Satellite Systems: Signal, Theory and Applications, Prof. Shuanggen Jin (Ed.), ISBN: 978-953-307-843-4, InTech, Available from: http://www.intechopen.com/books/global-navigation-satellite-systems-signal-theory-andapplications/ionospheric-propagation-effects-on-gnss-signals-and-new-correction-approaches

\section{INTECH}

open science | open minds

\author{
InTech Europe \\ University Campus STeP Ri \\ Slavka Krautzeka 83/A \\ 51000 Rijeka, Croatia \\ Phone: +385 (51) 770447 \\ Fax: +385 (51) 686166 \\ www.intechopen.com
}

\author{
InTech China \\ Unit 405, Office Block, Hotel Equatorial Shanghai \\ No.65, Yan An Road (West), Shanghai, 200040, China \\ 中国上海市延安西路65号上海国际贵都大饭店办公楼 405 单元 \\ Phone: +86-21-62489820 \\ Fax: +86-21-62489821
}


(C) 2012 The Author(s). Licensee IntechOpen. This is an open access article distributed under the terms of the Creative Commons Attribution 3.0 License, which permits unrestricted use, distribution, and reproduction in any medium, provided the original work is properly cited. 